\title{
3D noise mapping for preselected locations of urban area with and without noise barriers: A case study of Delhi, India
}

https://doi.org/10.1515/noise-2020-0006

Received Nov 18, 2019; accepted Mar 23, 2020

\begin{abstract}
Noise pollution has been rising as a critical issue in recent days particularly for the people living in urban areas. This study has been conducted to find out the effects of traffic induced noise on nearby residential building through 3D noise mapping with and without noise Barriers. Monitoring has been carried out at various densely populated preselected locations of Delhi, India. Thereafter, 3D noise mapping has been done using hourly average noise levels for the locations exposed with maximum noise. The developed 3D noise map shows the variation of noise level along $X, Y$ and $Z$ direction for all selected locations before and after installation of noise barriers. Moreover, the result also shows that exact assessment of noise impact is possible through 3D noise mapping, when a multistory building close to the source of noise is taken into consideration. This paper also elaborates the adequate height, distance and NRC value of noise barrier to reduce the effect of road traffic noise on nearby high rise building. Reduction pattern of noise level can easily be visualized and evaluated by using these maps. This type of study could support decision makers during adaptation of suitable remedial measures.
\end{abstract}

Keywords: noise barrier, noise levels, noise mapping, 3D noise maps

\footnotetext{
*Corresponding Author: Pervez Alam: Department of Civil Engineering, Engineering \& Technology, Jamia Millia Islamia, Jamia Nagar, New Delhi, 110025, India; Email: pervezjmi@gmail.com Kafeel Ahmad, S. S. Afsar: Department of Civil Engineering, Engineering \& Technology, Jamia Millia Islamia, Jamia Nagar, New Delhi, 110025, India

Nasim Akhtar: CSIR - Central Road Research Institute (CRRI), Delhi-Mathura Road, New Delhi, 110025, India
}

\section{Introduction}

We live in a noisy world and most of that noise is made by human's activities. Traffic, machinery, electronics are constant source of sound. It is the major source of dissatisfaction for environment in residential, commercial, industrial and institutional areas. Recent studies show that our increasingly loud world is having negative effects on health and environment. It has been observed that the noise affect the different group of people in different from if the noise levels remains between 30-60 dB (A) [1]. According to Cho et al. [2], noise mapping is the process of determining and visualizing noise impact on the environment in order to support environmental policies. The noise mapping concept is popular in the world as it is the graphical representation of the sound level distribution of a given region for a certain defined period. Mapping can be made about individual noise sources, i.e., road traffic, railway traffic, aircraft in flight or industry. However, all the sources can be combined into one map to give an overall picture of the noise climate. It was initially developed in the European countries and it is now extensively used [3]. Further the noise mapping was adopted in the other countries like Japan, Brazil, South Korea and United States [4-7]. Later the dramatic enhancement of computation speed, rapid development in Geographic Information System (GIS), three-dimensional (3D) computer graphic, virtual reality technology and the wide availability of digital topographic and mapping data have facilitated the substantial advancement in noise assessments and simulation. 2D GIS has been widely and successfully used in environmental impact studies and to assess the impact of spatial phenomena such as soil pollution, air pollution and noise on the environment. In rural areas, where noise does not vary significantly with height due to absence of obstacles, a 2D representation may still suffice. However it can be expected that a 3D approach can offer fundamental improvements when 3D effects are relevant i.e., in urban areas. 3D noise mapping over a large geographical area has now become a manageable task. Kluijvera and Stoterb [8]

əopen Access. () 2020 P. Alam et al., published by De Gruyter. (cc) BY License 


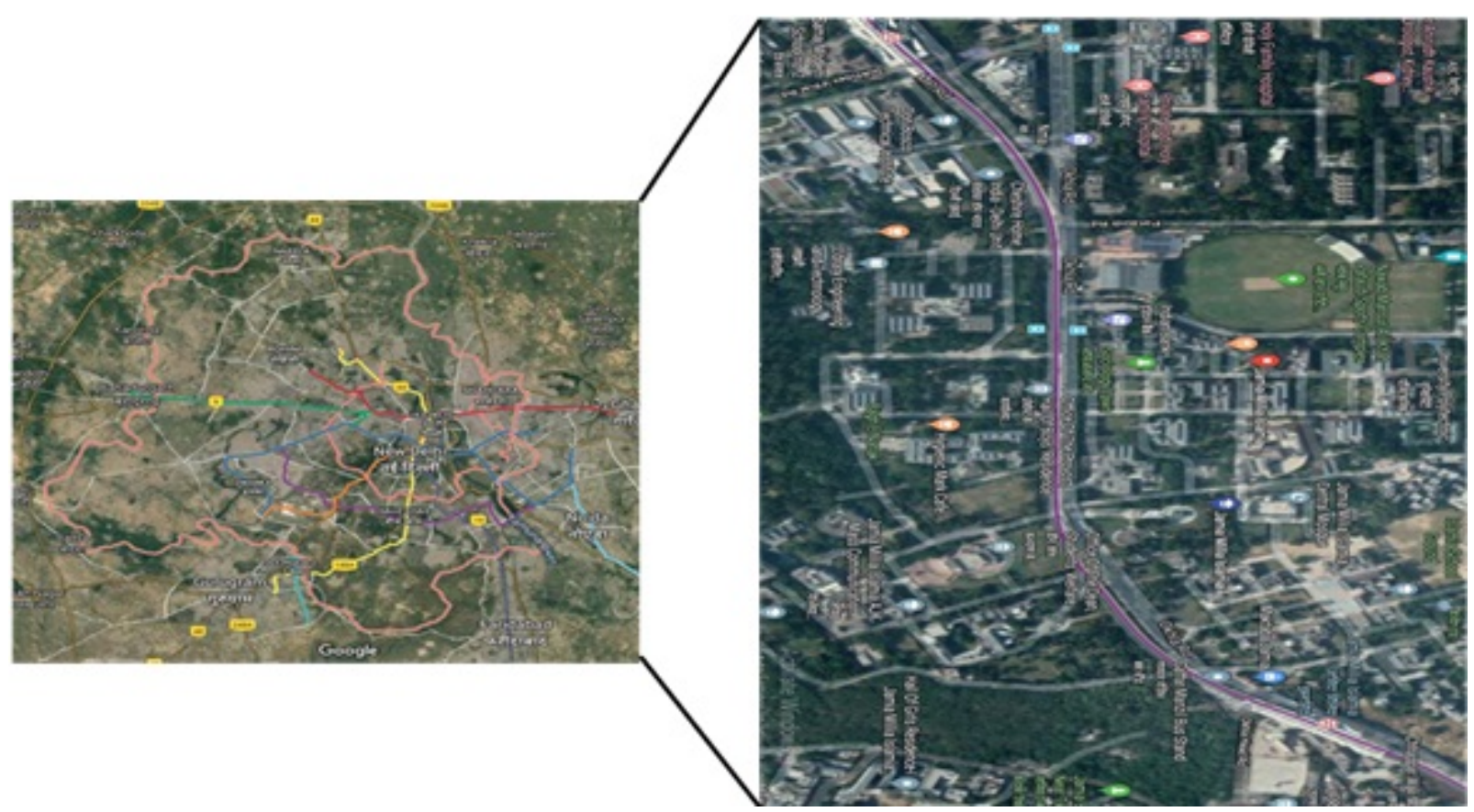

Figure 1: Study area for noise monitoring and 3D mapping (Source: Google map)

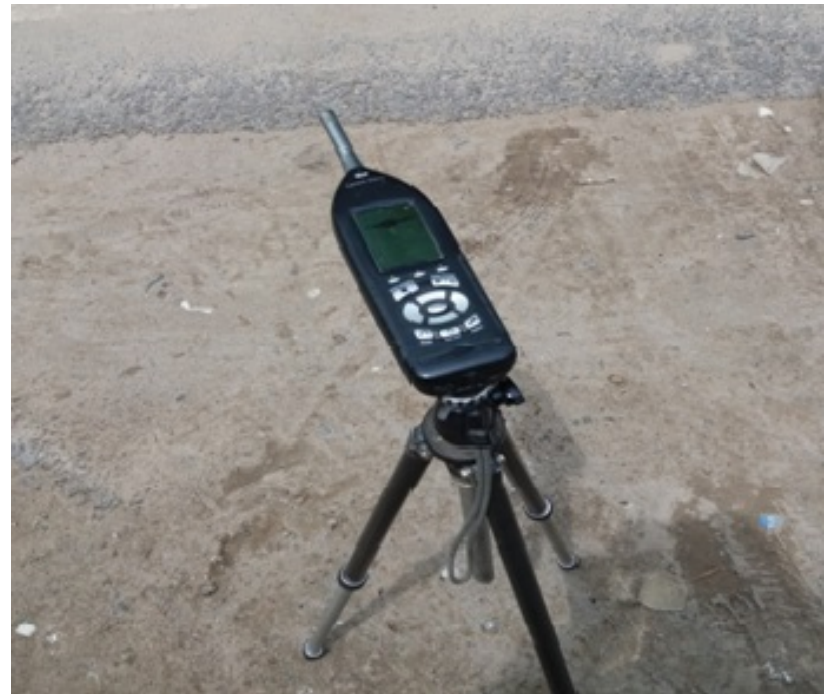

Figure 2: Sound Level Meter Larson and Davis-831

have carried out mapping through GIS results; their study states that the noise mapping through GIS may optimize quality and efficiency of noise studies. However improving the accuracy of noise models is an important scientific issue. In order to assess and monitor the influence of noise, different noise barriers have come to existence to control the noise pollution. Interest in noise barriers has been increased all over the world because of the extension of motorways in urban areas. In this situation, barriers could be useful in protecting noise-sensitive areas. Sev- eral methods of assessment of the performance of noise barriers are nowadays available, both from the measurement than form the simulation point of view. Maekawa [9] presented a design chart for noise mapping based partly on a review on noise and extension of the existing theory of noise and partly on experimental evidence. Later Rathe, [10] proposed a simplification of Maekawa's noise design chart. Many measurements of the performances of model barriers have been made either under anechoic conditions or under more realistic conditions yet still more work is required to coup up the influence of the weather [11-13]. Maekawa's outdoor experiments were limited to distances of up to $16 \mathrm{~m}$ from the barrier. Both Maekawa and Rathe concludes their papers by pointing out that at increased distances, vegetation, geometry of road and other factors influencing the propagation of sound need to be considered. Recent research into the subjective effects of traffic noise [14-19] has shown that, for a good correlatiotion with dissatisfaction, it is necessary to consider the continuous noise level as well as the noise peaks. Sonaviya and Tandel developed 2D noise maps for tier- 2 city urban roads. Kumar et al., have done their noise assessment, prediction and mapping study for city Vellore. They record highest Leq levels in evening (57.5-78.4 dB (A)) and afternoon (58.8-76.4 dB(A)) time during weekday and weekend, respectively [20]. So, for the results to closely relate to the dissatisfaction with traffic noise, the performance of barriers needs to be investigated in terms of both peak and con- 


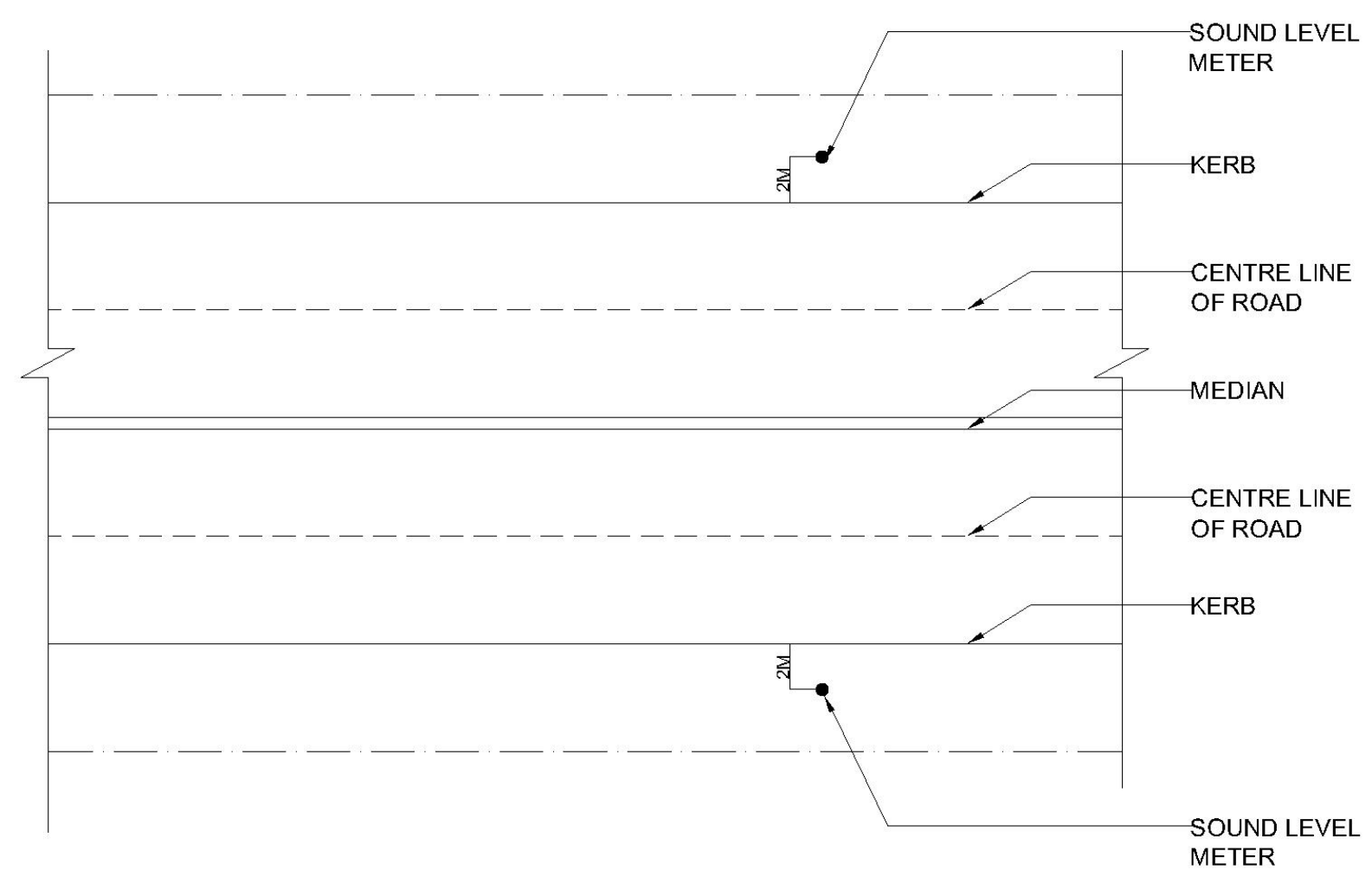

Figure 3: Position of sound level meter on both side of the road

tinuous noise. The literature survey shows that the effect of noise barrier in the propagation of sound is missing in urban settings of developing countries, which significantly affect the pattern of distribution of the noise levels. Therefore, the main objective of this paper is to investigate the effects of noise barrier in the propagation of sound using 3D noise mapping.

\section{Materials and method}

\subsection{Study area}

The study has been carried out at the densily populated road of Jamia Millia Islmia University, Sukhdev Vihar and Don Bosco Technical Institute in New Delhi India. The Jamia Millia Islamia is a Central University establish in
1920 and situated in Delhi. Campus covers around 21 acres of land and has seven faculties and thirty eight departments [21]. Don Bosco Technical Institute is also adjacent to Jamia Millia Islamia and has been established in 1971 for the economicaly weeker section of students. It is situated at $28^{\circ} 33^{\prime} 34.9^{\prime \prime} \mathrm{N} 77^{\circ} 16^{\prime} 35.3^{\prime \prime} \mathrm{E}$ in district south Delhi of Delhi. Sukhdev Vihar is very near to Don Bosco Technical Institute and situated at $28^{\circ} 33^{\prime} 35.6^{\prime \prime} \mathrm{N} 77^{\circ} 16^{\prime} 30.5^{\prime \prime} \mathrm{E}$.

\subsection{Instrument and software used}

Two Larson \& Davis sound level meters has been used for noise monitoring. As shown in Figure 2 Sound level meter has been fixed on tripod stand to maintain proper height. MapInfo Pro v17 and Predictor LimA (Desktop) software's have been used for analysis and visualization of noise monitoring results. MapInfo Pro has been used to 


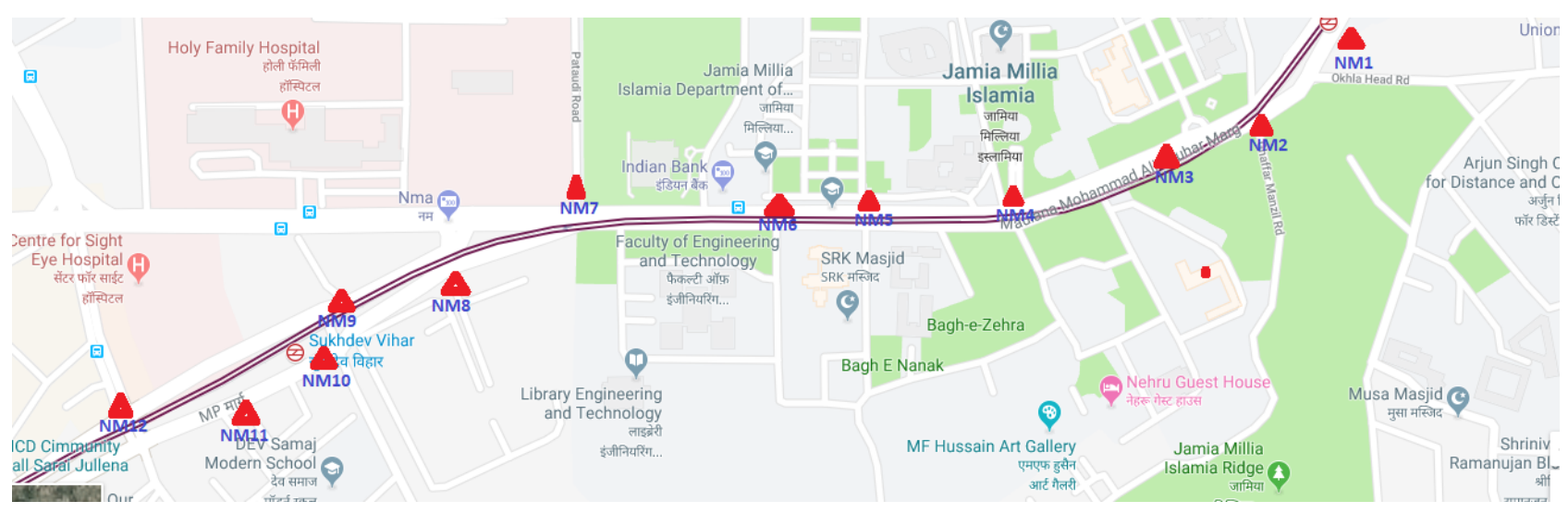

Figure 4: Temporary noise monitoring station for hourly average noise monitoring

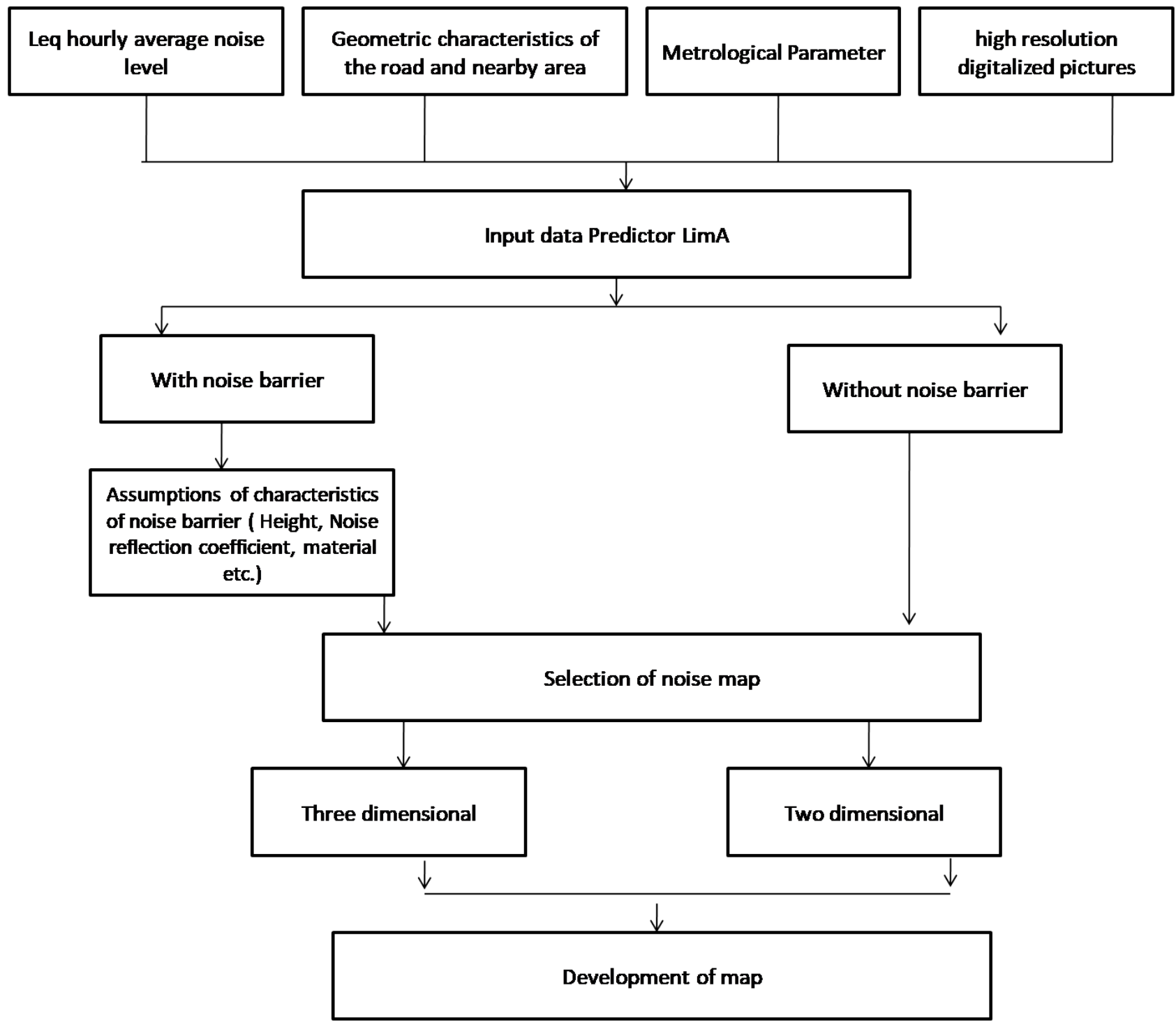

Figure 5: Noise mapping procedure 


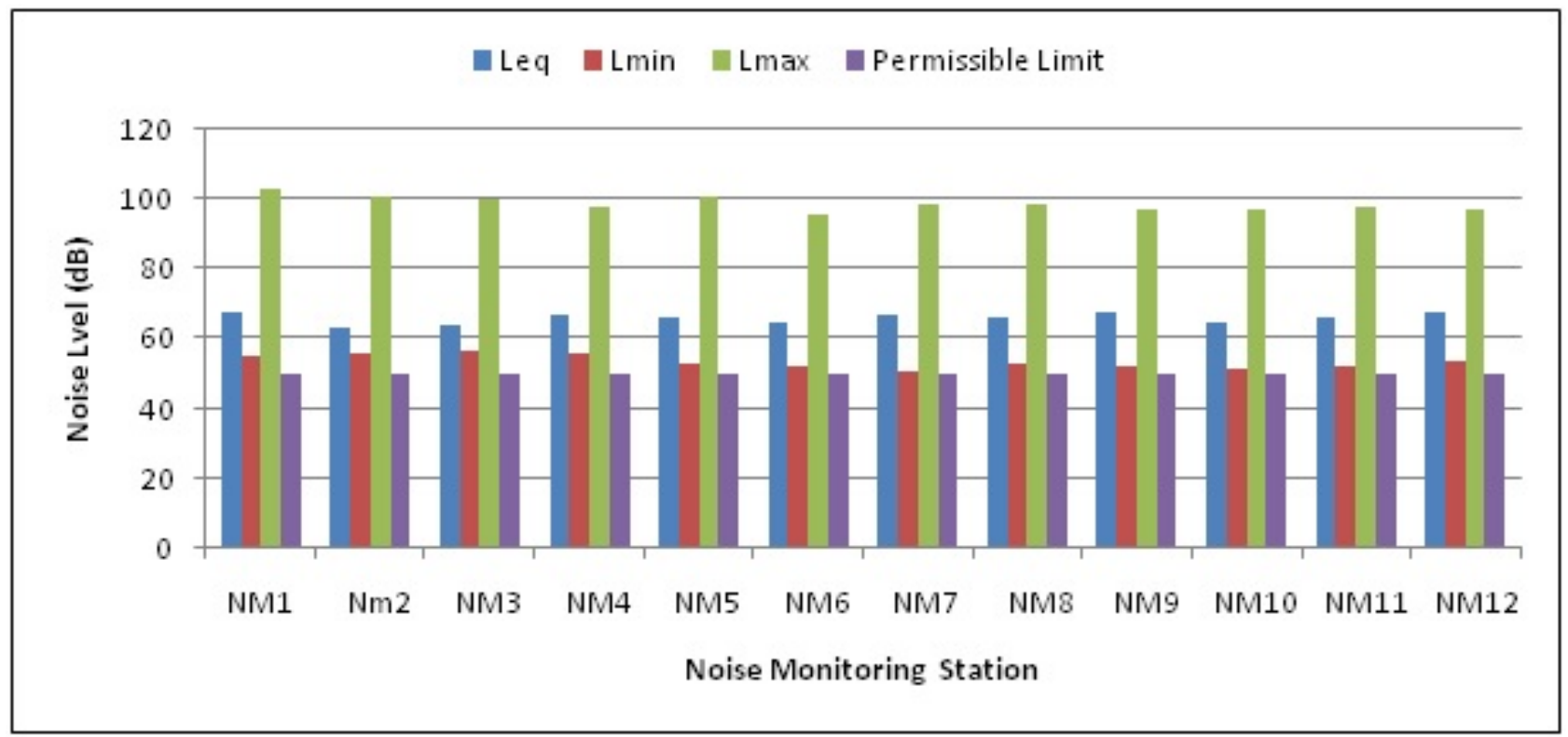

Figure 6: Hourly average variation of Leq (A), Lmax, Lmin and Permissible noise level at study area in day time

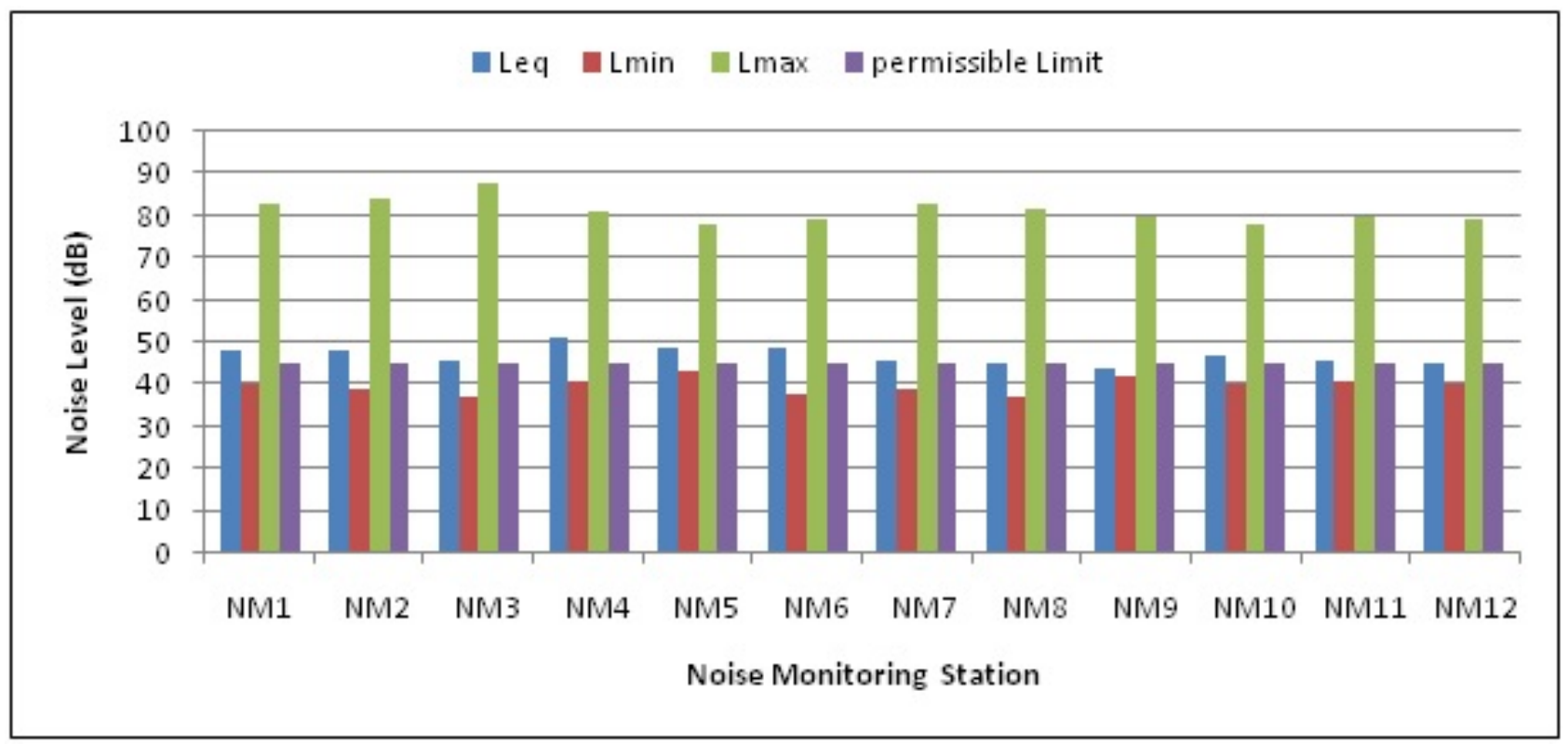

Figure 7: Hourly average variation of Leq (A), Lmax, Lmin and Permissible noise level at study area in night time

digitize the map and the same has been used for 3D noise mapping.

\subsection{Noise monitoring procedure}

The monitoring has been done using standard procedure as per Central Pollution Control Board (CPCB). CPCB is a constitutional body of India, was constituted in September, 1974. In 2015 CPCB has notified noise ambient moni- toring procedure to resolve the public complain. As shown in Figure 4 twelve temporary monitoring stations has been located at the study area in order to measure hourly averaged sound pressure levels. Care has been taken to establish noise monitoring at all junction where traffic either merges or diverts. As shown in the Figure 3, two sound level meters have been used on both sides of the road for noise monitoring in the day and night time. Furthermore, the noise monitoring result has been used for noise map- 


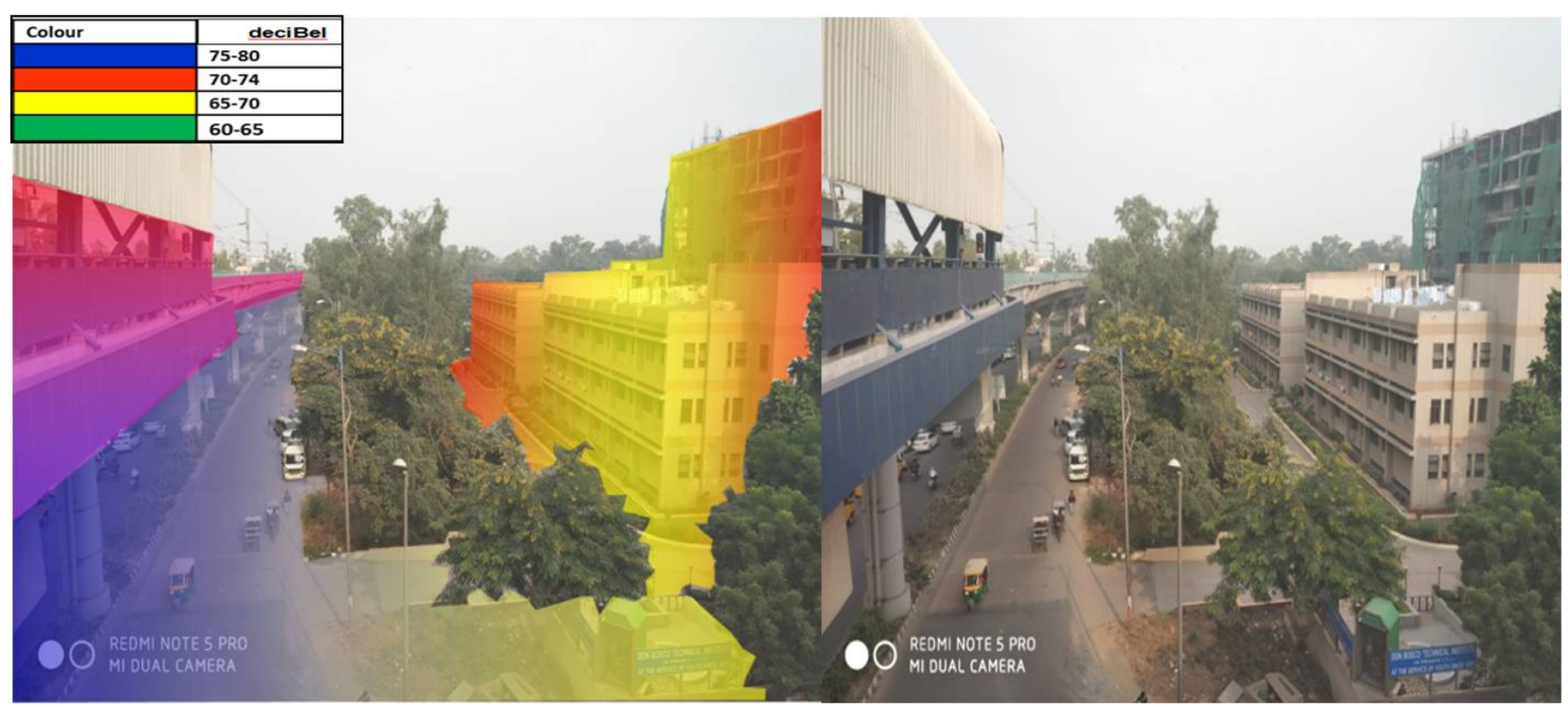

Figure 8: 3D noise mapping of Don Bosco Technical Institute area before installation of noise barrier

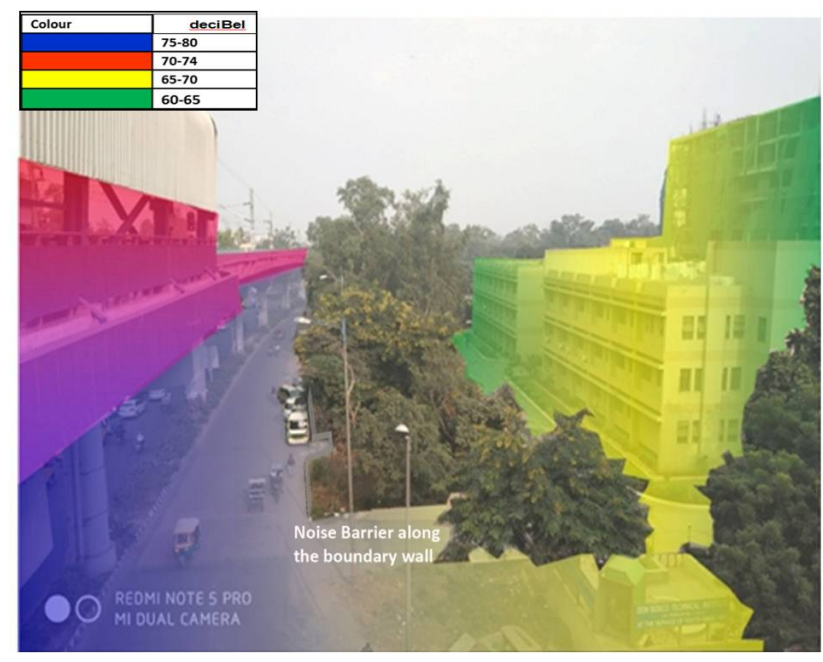

Figure 9: 3D noise mapping of Don Bosco Technical Institute area after installation of noise barrier

ping using Predictor LimA. The following step wise procedure has been adopted for noise mapping.

\subsection{Noise mapping procedure}

In this study, Predictor LimA (Desktop) has been used for the development of 3D noise maps. It can develop 3D noise maps for residential area, open environment and for road traffic using geometry of road and traffic information. Figure 5 shows the noise mapping procedure used to developed 3D noise maps. Hourly average Leq(A) noise level, hourly variation of traffic, composition of traffic, geomet- ric characteristics of road and nearby area, metrological parameters and high resolution digitalized pictures are required for development of noise map. Predictor LimA can develop noise map with and without noise barrier. If one select map with noise barrier, simulation software assumes a virtual noise barrier on the periphery of the road. The salient characteristics of noise barrier such as height, noise reflection coefficient, material, top tilted etc. have to be assumed before development of noise maps.

\section{Result and discussion}

The noise monitoring and mapping results with and without noise barrier for the study area for day time (6 AM to 10 $\mathrm{PM}$ ) and night time (10 PM to $6 \mathrm{AM}$ ) are presented and discussed in the following sections. The trend of maximum, minimum and equivalent noise levels along with comparison with prescribed standards are also discussed herein.

\subsection{Noise monitoring}

The Leq (A), Lmax, Lmin and Leq(A) permissible limit of noise level of the study area in day time is shown in Figure 6. The Lmax noise level has been registered as $103 \mathrm{~dB}(\mathrm{~A})$ at noise monitoring(NM) station.1 which remains maximum amongst all monitoring stations. At most of the places the Leq noise level remains more than $65 \mathrm{~dB}(\mathrm{~A})$ in day time. Monitoring results has been compared with the prescribed standards of CPCB (Central Pollution Control Board). It 


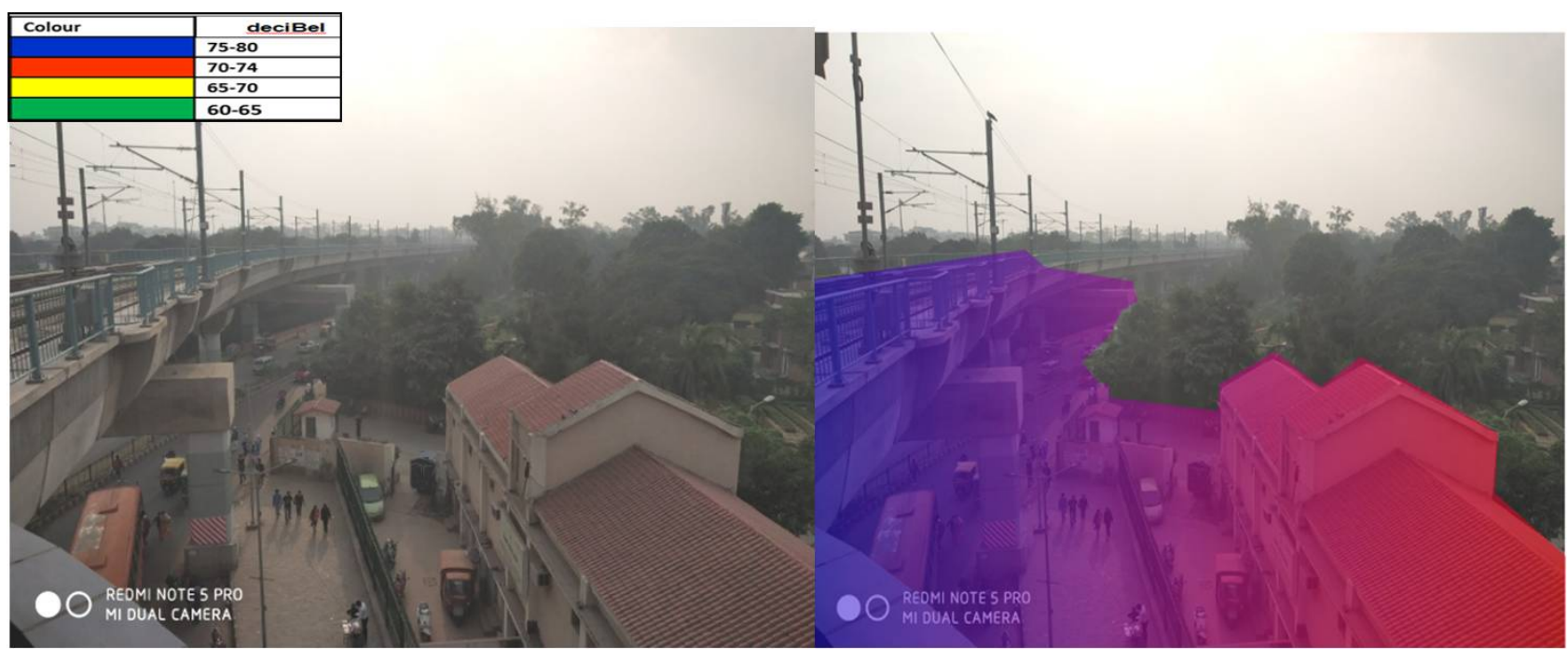

Figure 10: 3D noise mapping of Jamia Millia Islamia (Maktba) before installation of noise barrier

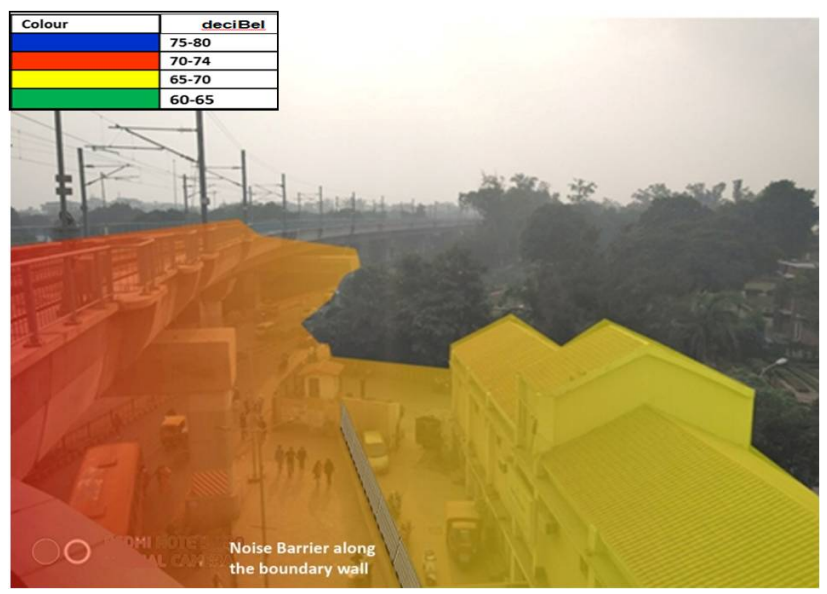

Figure 11: 3D noise mapping of Jamia Millia Islamia (Maktba) after installation of noise barrier

shows that the noise level in day time always remains more than the prescribed standard at all monitoring locations.

Hourly average variation of noise level for night time has been shown in Figure 7. It revealed that all noise monitoring stations are exposed to a noise level of more than the prescribed standard of CPCB. $88 \mathrm{~dB}$, Lmax noise level has been registered at monitoring station. 3 followed by 83 $\mathrm{dB}$ at NM7. Whereas, $51 \mathrm{~dB}$, Leq level has been registered at NM4 four followed by $49 \mathrm{~dB}$ at NM6.

\subsection{Noise mapping}

\subsubsection{Don Bosco Technical Institute area}

3D noise map of Don Bosco Technical Institute Area is shown in Figure 8. It reveals that the noise level at the center of the road nearby Don Bosco Technical Institutional area noise level remains in between 70 and $75 \mathrm{~dB}(\mathrm{~A})$ in peak hours, and it is around $60 \mathrm{~dB}(\mathrm{~A})$ in lean hours. 3D noise map also shows that the nearby building of institutional area receives a sound pressure level of more than 70 $\mathrm{dB}$ (A) up to a height of $10.5 \mathrm{~m}$; it reduces and reached up to $60 \mathrm{~dB}(\mathrm{~A})$ after $10.5 \mathrm{~m}$ height.

The observed noise level is more than enough to create discomfort to the students studying in the technical institute. To cater the high noise level a structure mounted virtual noise barrier with top tilted of a height of $2.0 \mathrm{~m}$ with noise reduction coefficient of 0.70 has been assumed at the periphery of main road. As shown in Figure 9 the 3D noise map after installation of noise barrier helps in to reduce the noise level below the regulatory standard at Don Bosco Technical Institutional Area. The noise level reduced to 55$60 \mathrm{~dB}(\mathrm{~A})$ which was $70 \mathrm{~dB}(\mathrm{~A})$ before assumption of noise barrier.

\subsubsection{Jamia Millia Islamia}

The 3D noise map of Jamia Millia Islamia (Maktba) before installation of noise barrier revealed that the noise level at the center of the road nearby Jamia Millia Islamia (Maktba) area ranges between 75 and $80 \mathrm{~dB}(\mathrm{~A})$ in peak hours and it is around $70 \mathrm{~dB}(\mathrm{~A})$ in lean hours. It also shows that 


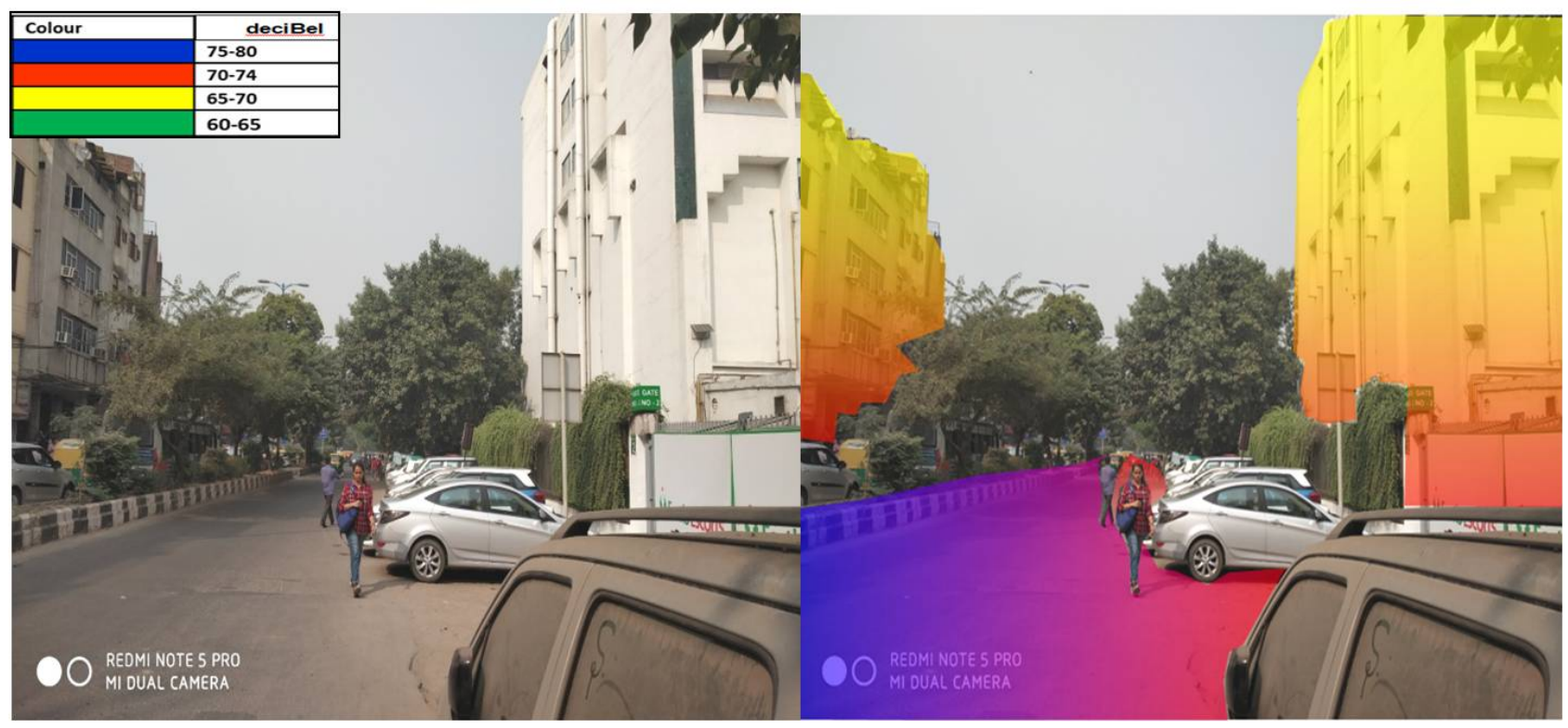

Figure 12: 3D noise mapping of Sukhdev Vihar before installation of noise barrier

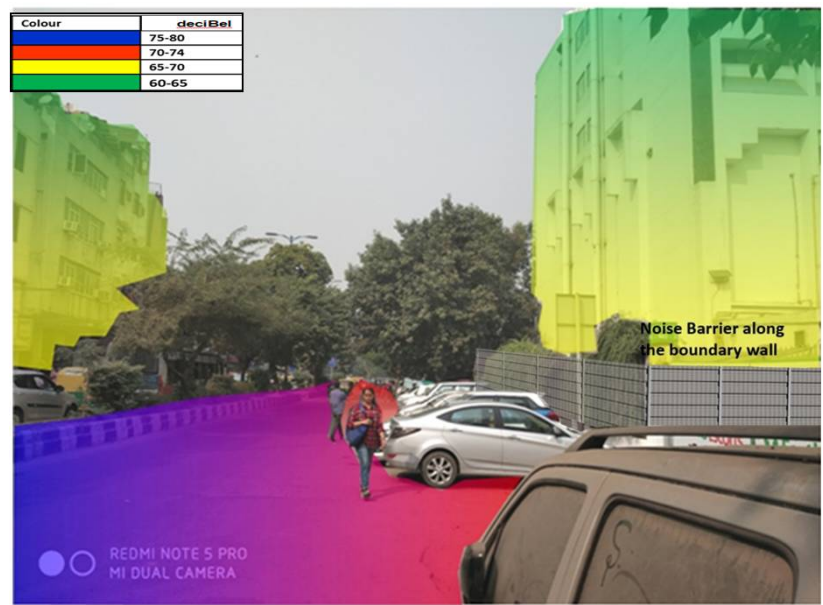

Figure 13: 3D noise mapping of Sukhdev Vihar after installation of noise barrier

the nearby building of Jamia Millia Islamia has received a noise level of more than $75 \mathrm{~dB}$ (A) up to a height of $8.5 \mathrm{~m}$; it reduces and reached up to $60 \mathrm{~dB}(\mathrm{~A})$ after installation of noise barrier.

The monitored noise level is more than enough to produce discomfort to the students studying in the silent zone of Jamia Millia Islamia (Maktaba). Figure 11 shows the 3D noise map of Jamia Millia Islamia (Maktba) after assumption of virtual of noise barrier. A structure mounted noise barrier with top tilted of a height of $2.5 \mathrm{~m}$ with noise reduction coefficient of 0.8 has been assumed around the periphery of main road. The developed 3D map shows that noise barrier helps in to reduce the noise level nearby the regulatory standard in day time i.e., up to $50 \mathrm{~dB}(\mathrm{~A})$.

\subsubsection{Sukhdev Vihar}

Sukhdev Vihar is the densely populated residential area situated in south Delhi. The traffic volume remains very high in peak hours at the major road of Sukhdev Vihar. As shown in Figure 12 the 3D noise map of the major road of Sukhdev Vihar before installation of noise barrier revealed that the noise level remains maximum at the central line of the road i.e., (75-80 dB) and decreases with distance but still affects the nearby residential building with a noise level of $65-70 \mathrm{~dB}$ up to a height of $13.5 \mathrm{~m} .65 \mathrm{~dB}$ noise levels are sufficient to create discomfort to the residence living nearby road.

Measures are required to reduce the propagation of noise from road. A 3D noise map has been developed after assumption of virtual noise barrier that may be act as an obstruction to reduce the propagation of sound to the nearby residential area. As shown in Figure 13 a noise barrier with top tilted of a height of $2.0 \mathrm{~m}$ with noise reduction coefficient of 0.7 is assumed around the periphery of main road. The developed noise map shows that the noise level is reduced below the regulatory standard in day time i.e., up to $55 \mathrm{~dB}(\mathrm{~A})$. 
Table 1: Validation of 3D noise map

\begin{tabular}{ccccc}
\hline S.No & $\begin{array}{c}\text { Height } \\
\text { (From Bottom of Building) }\end{array}$ & $\begin{array}{c}\text { Noise Level dB (A) } \\
\text { (Simulated) }\end{array}$ & $\begin{array}{c}\text { Noise Level dB (A) } \\
\text { (Measured) }\end{array}$ & $\begin{array}{c}\text { Standard } \\
\text { Deviation }\end{array}$ \\
\hline 1. & $1.5 \mathrm{~m}$ & 70.2 & 69.3 & 0.45 \\
2. & $3.0 \mathrm{~m}$ & 68.3 & 66.4 & 0.95 \\
3. & $4.5 \mathrm{~m}$ & 63.2 & 62.6 & 0.42 \\
4. & $6.0 \mathrm{~m}$ & 62.1 & 61.7 & 0.34 \\
5. & $7.5 \mathrm{~m}$ & 60.3 & 59.2 & 0.51 \\
6. & $9.0 \mathrm{~m}$ & 56.1 & 55.1 & 0.67 \\
\hline
\end{tabular}

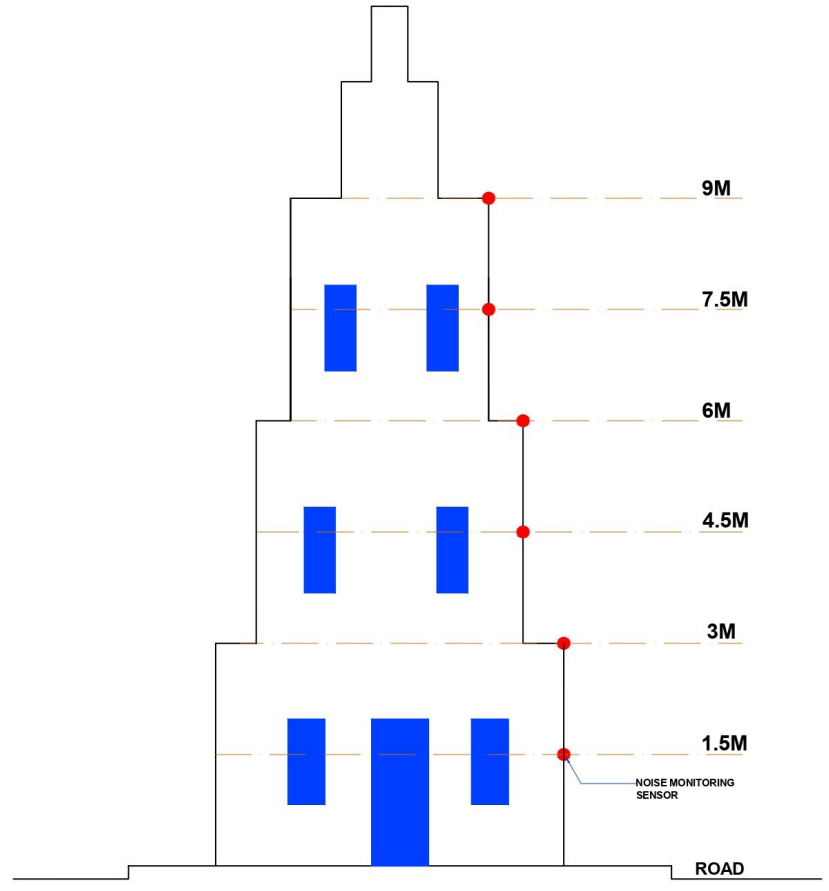

Figure 14: Location of noise monitoring sensors for validation of 3D noise maps

\section{Validation of 3D noise maps}

3D noise maps have been validated using monitored data, standard deviation for the monitored data and predictor data has been calculated as shown in Table 1. For validating the 3D noise mapping results, sensors have been installed at different height of Jamia Millia Islamia (Maktba) with an interval of $1.5 \mathrm{~m}$ from bottom shown in Figure 14. The maximum standard deviation of 0.95 has been found at a height of $3.0 \mathrm{~m}$ from bottom and minimum has been found 0.34 at a height of $6.0 \mathrm{~m}$ from bottom. Validation of results also revealed that the 3D noise mapping using Predictor LimA gives very accurate results which may further be used by the decision maker for remedial measures.

\section{Conclusion}

This study has been conducted to prove how an impact study of a spatial phenomenon can be improved by providing a 3D mapping approach. Thirteen temporary noise monitoring stations have been used to carry out this study. Based on monitoring results out of thirteen noise monitoring stations three has been selected as critical. 3D noise map has been developed with and without noise barrier for the critical locations to show the effects of traffic noise on nearby residential buildings and how noise barriers play vital role in noise reduction. From the results, it has been concluded that the 3D noise maps can offers significant insight in urban areas. It is also concluded that the 3D noise mappings is a very effective approach for understanding through an immediate visualization the distribution of noise level of any area. 3D noise mapping will also remains very useful for the decision makers for identifying the critical locations in terms of $\mathrm{X}, \mathrm{Y}$ and $\mathrm{Z}$ direction that require urgent noise remediation.

\section{References}

[1] Environmental Noise Guidelines for the European Region by the World Health Organization; World Health Organization 2018.

[2] Cho D.S., Kim J.H., Manvell D., Noise mapping using measured noise and GPS data, Appl. Acoustic, 2007, 68, 1054-1061.

[3] Piedada O.M., Bavyer M.E., Clodovou D., Planning the Acoustic Urban Environment: A GIS Centred Approach, Int. Semp. on ACM GIS 99, 1999, Kansas, USA.

[4] European parliament and of the council. Relating to the assessment and management of environmental noise. Directive 2002/49/Ec:2002.

[5] Shi W., Seo I.C., Young M., Utilizing noise mapping for environment impact assessment in downtown redevelopment areas of Seoul, Korea, Appl. Acoustic, 2008, 69, 704-714.

[6] Pinto A., Mardones D.M., Noise mapping of densely populated neighbourhoods-example of Copacabba, Rio de Janerioo- Brazil, Environ. Monitor. Assessm., 2009, 155, 9-18. 
[7] Kenneth K., Eddie D., James C., Community and regional noise mapping in the United States, Sound Vibr., 2007, 9, 7-14.

[8] Kluijver H., Stoterb J., Noise mapping and GIS: optimising quality and efficiency of noise effect studies, Compo Environ. Urban System, 2003, 27, 85-102.

[9] Maekawa Z., Noise reduction by screens, Appl. Acoustic, 1968, 1, 157-163.

[10] Rathe E.J., Sound Vibration, Note on two common problems of sound propagation, 1969.

[11] Akhtar N., Ahmad k., Road Traffic Noise Mapping and a Case Study for Delhi. Int. J. Appl. Eng. Technol., 2012, 2, 39-45.

[12] Guedes I. C. M., Bertoli S. R., Zannin P.H.T., Influence of urban shapes on environmental noise: A case study in Aracaju - Brazil, Science Total Environment 2011, 76, 412-413.

[13] Arenas C., Leiva C., Vilches L.F., Technical specifications for highway noise barriers made of coal bottom ash-based sound absorbing concrete, Constr. Build Mater., 2015, 95, 585-591.

[14] Hueso M.C., Gimenez S.A.S., Gaja E., Measurement techniques of noise level in various urban scenarios - Day selection and representative perio, Appl. Acoust., 2017,116, 216-228.
[15] Alias F., Rosa A., Orga F., Socoro J., Detection of Anomalous Noise Events for Real-Time Road-Traffic Noise Mapping: The DYNAMAP's project case study, Noise Mapp., 2018, 5, 71-85,.

[16] Merchan C. I., Diaz B. L., Noise pollution mapping approach and accuracy on landscape scales, Sci. Total Environ., 2013, 449, 15-25.

[17] Joshi A.N., Joshi N.C., Rane P.P., Noise Mapping in Mumbai City, India, 2015, 2, 380-385.

[18] Pinto F.A., Mardones M.D., Noise mapping of densely populated neighborhoods - example of Copacabana, Rio de Janeiro - Brazil, Environ. Monitor. Assessm., 2009, 155, 309-318.

[19] Billah M., Rahman G.A., Land cover mapping of Khulna city applying remote sensing technique. In Proceedings of the 12th International Conference on Geo-informatics (Sweden: Geospatial Information Research: Bridging the Pacific and Atlantic, University of Gavle) 2004, 04, 707-714,.

[20] Kumar M.N., Basha K., Srimuruganandam B., Assessment, Prediction and Mapping of Noise Levels in Vellore City, India; Noise Mapp., 2019, 6, 38-51.

[21] "Profile on Jamia Millia Islamia" (PDF). Jamia Millia Islamia, Retrieved: 2019-01-15, Google maps. 